\title{
EXPERIÊNCIAS FORMATIVAS NO PROGRAMA RESIDÊNCIA PEDAGÓGICA DA ÁREA DE CIÊNCIAS DA NATUREZA
}

Fabiane de Andrade Leite ${ }^{1}$

Judite SCHERER WenZeL ${ }^{2}$

\section{Introdução}

A formação de professores tem sido tema de estudos e de pesquisas há muito tempo no Brasil, com mais ênfase a partir dos últimos anos do século XX, período em que foram instituídas políticas públicas voltadas para a qualificação profissional docente (GATTI, 2008). Nesse período, concentrou-se o surgimento de diversos tipos de formação que

[têm] base histórica em condições emergentes na sociedade contemporânea, nos desafios colocados aos currículos e ao ensino, nos desafios postos aos sistemas pelo acolhimento cada vez maior de crianças e jovens, nas dificuldades do dia-a-dia nos sistemas de ensino, anunciadas e enfrentadas por gestores e professores e constatadas e analisadas por pesquisas. (GATTI, 2008, p. 58)

\footnotetext{
1 Doutora em Educação nas Ciências, professora-adjunta da UFFS, coordenadora de núcleo do Programa de Residência Pedagógica Multidisciplinar (Biologia, Física e Química) campus Cerro Largo. Contato: fabiane.leite@uffs.edu.br.

2 Doutora em Educação nas Ciências, professora-adjunta da UFFS, colaboradora de núcleo do Programa de Residência Pedagógica Multidisciplinar (Biologia, Física e Química) campus Cerro Largo. Contato: juditescherer@uffs.edu.br.
} 
Passadas mais de duas décadas da intensificação nos estudos acerca dos processos de formação de professores, a vigilância acadêmica permanece e tem buscado analisar " [...] os cursos de formação inicial, o professor e seus saberes, práticas, opiniões e representações” (ANDRÉ, 2010, p. 176). E é a partir desse movimento de pesquisa que temos nos mobilizado para compreender aspectos na formação inicial e continuada que contribuam com o desenvolvimento profissional dos professores, de modo especial junto ao Programa Residência Pedagógica (RP), no qual atuamos como coordenadoras.

Nossos diálogos e estudos corroboram com as ideias apresentadas por diversos autores (ALARCÃO, 2011; BOLZAN, 2002; IMBERNÓN, 2011; 2016; LARROSA, 2015; NÓVOA, 1995), que defendem a formação de professores reflexivos como alicerce para o desenvolvimento profissional e, para isso, acenam para as vivências como elementos essenciais nos processos de formação inicial e continuada do professor. Vivências que, de acordo com Imbernón (2011, p. 22), promovem a "inovação a partir de dentro" e, assim, se tornam experiências, no sentido apresentado por Larrosa (2015). E, para tanto, como modo de qualificar tal movimento formativo, temos apostado na prática da escrita reflexiva em Diário de Bordo (DB).

Ao considerar o contexto de formação inicial de professores, compreendemos que as vivências em espaço escolar podem se constituir experiências profícuas ao futuro professor e qualificar os que estão em atividade profissional. Para tanto,

[...] a experiência, a possibilidade de que algo nos aconteça ou nos toque, requer um gesto de interrupção, um gesto que é quase impossível nos tempos que correm: requer parar para pensar, parar para olhar, parar para escutar, pensar mais devagar, olhas mais devagar, e escutar mais devagar; parar para sentir, sentir mais devagar, demorar-se nos detalhes, suspender a opinião, suspender o juízo, suspender a vontade, suspender o automatismo da ação, cultivar a atenção e a delicadeza, abrir os olhos e 
os ouvidos, falar sobre o que nos acontece, aprender a lentidão, escutar aos outros, cultivar a arte do encontro, calar muito, ter paciência e dar-se tempo e espaço. (LARROSA, 2015, p. 25)

As reflexões realizadas nas escritas em $\mathrm{DB}$ evidenciam que as vivências realizadas nos espaços escolares qualificam o processo formativo de forma mais intensa do que os compartilhamentos socializados acerca do processo de desenvolvimento de uma aula. Dessa forma, percebemos que algumas vivências foram mais marcantes do que outras, ou seja, expressaram de forma mais sentimental aspectos que lhes aproximaram do ser professor.

Entre as vivências compartilhadas, destacamos, no presente capítulo, as que apresentam aspectos que, de acordo com Larrosa (2015, p. 16), produziram sentido, criando realidade, funcionando como "potentes mecanismos de subjetivação". Assim, ao ler os diários dos participantes do Programa RP, fomos surpreendidas pelas palavras e depoimentos transcritos que refletem angústias, potencialidades e marcam a trajetória formativa desses professores em formação e, assim, como Larrosa (2015), apontamos para a importância no uso das palavras, pois elas "determinam nosso pensamento" (LARROSA, 2015, p. 16) e dão sentido "ao que somos e ao que nos acontece". Percebemos que as palavras escritas nos DB eram mais do que simples palavras, eram marcas constitutivas da formação que se tornam experiência docente.

Assim, considerando nossa inserção como coordenadoras de um núcleo Multidisciplinar da área de Ciências da Natureza do Programa Residência Pedagógica (RP) na UFFS - campus Cerro Largo, $\mathrm{RS}$, temos intensificado nossos estudos e direcionado nossos olhares para as reflexões compartilhadas pelos participantes do Programa quanto às contribuições do processo formativo vivenciado na busca de um constante desenvolvimento profissional, então, são essas marcas que apresentamos como categorias formativas da nossa 
experiência com o RP. A fim de contextualizar as ações formativas vivenciadas em tal programa, segue uma descrição mais detalhada de como foi o processo de implementação das ações que estão sendo desenvolvidas junto ao RP e, na sequência, apresentamos as categorias que emergiram da análise das escritas dos DB e que retratam a importância de tal contexto formativo como precursor de experiências.

\section{O Programa de Residência Pedagógica na Formação Inicial de Professores}

O programa RP iniciou atividades na UFFS a partir do encaminhamento de um projeto institucional ao Edital n. 06/2018 da CAPES $^{3}$ em maio de 2018, iniciando as atividades no mês de agosto do mesmo ano. O projeto apresenta como objetivo principal,

[...] fortalecer e qualificar o trabalho de Estágio Curricular Supervisionado, por meio de estudos pertinentes ao exercício da docência, da imersão coletivamente planejada e sistemática do aluno de licenciatura visando a vivência e a experimentação de situações concretas do cotidiano escolar e da sala de aula e do estreitamento permanente da relação entre os Cursos de Licenciatura da UFFS e a Educação Básica. (UFFS, 2018, p. 2)

Os participantes do Programa consistem nos coordenadores, que são professores formadores da Instituição de Ensino Superior, os residentes, que são os licenciandos, e os preceptores ${ }^{4}$, que são os

\footnotetext{
3 Coordenação de Aperfeiçoamento de Pessoal de Nível Superior.

4 Cabe destacar que este nome não foi incorporado no dia a dia da escola. Em visitas realizadas, identificamos certa resistência dos professores em fazer referência ao preceptor, sejam colegas ou até mesmo os próprios preceptores. Também nós, coordenadores, reconhecemos que há dificuldades em relacionar o professor do programa RP como um preceptor, pois, de acordo com o dicionário Aurélio, preceptor se refere "àquele que ministra preceitos ou instrução" (FERREIRA, 2010), o
} 
professores da Educação Básica que acompanham e auxiliam no trabalho in loco dos residentes. Para estabelecer um coletivo entre os integrantes do programa RP, realizamos diferentes ações de formação, de planejamento de atividades do residente e da sua inserção nas escolas.

Destacamos que o processo de formação foi realizado de forma mais intensificada nos primeiros dois meses do programa na universidade. Nessa etapa, residentes e preceptores realizaram oito horas semanais de leituras dirigidas e estudos, em especial do documento da Base Nacional Comum Curricular (BNCC). Em um segundo momento, cada residente elaborou um Plano de Ações do Residente (PAR) de forma colaborativa com um preceptor e com a orientação dos coordenadores. Na sequência, os residentes foram alocados nas escolas para realizar, em um período de seis semanas, o processo de ambientação, que foi finalizado com a socialização de um relato acerca da sua vivência em contexto escolar. E, finalmente, a realização de 100 horas de atividades docentes em sala de aula, que foram organizadas em 50 horas para atuação em turmas de Ensino Fundamental e as outras 50 horas em turmas de Ensino Médio, sendo que todas essas ações são permeadas de estudos e de planejamentos coletivos na Universidade ${ }^{5}$.

Nosso núcleo conta com 27 residentes, sendo 24 bolsistas e três voluntários; destes, 24 estão cursando Licenciatura em Ciências Biológicas, dois o curso de Química Licenciatura e um residente matriculado no curso de Física Licenciatura. Ainda, temos três professores preceptores com formação na área de Ciências da Natureza, atuando em duas escolas da rede pública estadual, sendo dois professores na Escola Estadual Técnica Guaramano e uma professora na Escola

que não sustenta a função que implica um acompanhamento coletivo e não apenas direcionado por eles.

${ }^{5}$ Estas atividades ainda estão em andamento. 
Estadual de Ensino Médio João Przyczynski, ambas no município de Guarani das Missões, RS, situadas a $20 \mathrm{~km}$ da sede da universidade. Destacamos que as escolas, inseridas no programa RP, ainda não tinham recebido a oportunidade de realizar ações tão sistemáticas com a universidade.

Nesse contexto, inserimos instrumentos formativos para auxiliar no desenvolvimento profissional por meio da reflexão na ação. Nossa escolha se deu na prática da escrita em diário de bordo. Destacamos que o instrumento formativo tem sido sistematicamente utilizado pelo Grupo de Estudos e Pesquisa em Ensino de Ciência e Matemática (GEPECIEM), do qual fazemos parte. Tal perspectiva formativa se caracteriza como ações de formação que contemplam a investigação-ação emancipatória, conforme proposto por Carr e Kemmis (1988). O uso do diário de bordo tem sido estratégia recorrente em nossos projetos, pois potencializa o processo de refletir na ação, conforme apresentado por Porlán e Martín (2000, p. 23, tradução nossa), “[...] sua utilização periódica permite refletir acerca do ponto de vista do autor sobre os processos mais significativos da dinâmica em que está imerso".

E, as análises das escritas dos DBs dos residentes e dos preceptores, além dos compartilhamentos socializados ao longo do período de realização das ações no programa, nos possibilitam dialogar acerca da vivência formativa e de indiciá-la como experiência marcante na constituição docente dos participantes. As leituras dos DBs e os diálogos formativos estabelecidos nos permitem, ainda, indicar algumas categorias formativas, quais sejam: a) o planejamento e o agir na incerteza para os residentes; e para os preceptores, identificamos: b) coletivo e desenvolvimento profissional. Na sequência, passaremos a relatar de que forma foi possível indiciar as categorias em cada um dos grupos.

Ressaltamos que ambas não são excludentes no processo de formação e/ou prática docente, apenas ficaram mais enfatizadas em 
cada um dos grupos em função da sua realidade e/ou necessidade formativa. Os professores que atuam nas escolas sentem necessidade de um coletivo, de um trabalho colaborativo e de espaços que possibilitem a prática da leitura e da escrita em um movimento que também retrata uma valorização profissional. Já os residentes indicam a sua angústia sobre o planejamento e as realidades escolares, pois percebem a necessidade formativa de um bom planejamento e de uma necessária formação teórica para, assim, conseguir tomar as decisões que urgem no contexto escolar. Ou seja, cada uma das categorias está interligada com o processo temporal vivenciado pelos sujeitos, uma mais vinculada à formação continuada e outra mais relacionada à formação inicial. Segue um diálogo em relação às categorias que emergiram do processo formativo e que indicam a importância da inserção do Programa RP no contexto de formação de professores.

a) Planejamento e Agir na Incerteza

[...] Foram inúmeras noites com o planejamento, bastante cansativo e complexo, mas também com muitas aprendizagens [...]

[...] Planejei toda a aula em slides... e me frustrei bastante, o equipamento não funcionou e todas as imagens lindas que eu havia escolhido não serviram para nada [...]

As escritas pinceladas dos DBs de dois residentes indicam angústias e retratam as especificidades da docência, a necessidade do planejamento e a mudança em contexto da prática, o que reforça a necessidade de uma relação teoria prática. Nisso está implícito também as especificidades dos conhecimentos necessários do professor e da sua profissionalidade.

Imbernón (2011, p. 31) contribui com o que foi exposto ao afirmar que o desenvolvimento profissional requer 
[...] conhecimento polivalente que compreenda diferentes âmbitos: o sistema [...], os problemas que dão origem à construção dos conhecimentos, o pedagógico geral, o metodológico-curricular, o contextual e o dos próprios sujeitos da educação.

Nesse sentido, podemos afirmar que as vivências realizadas pelos residentes têm possibilitado o desenvolvimento do conhecimento polivalente, tanto nos encontros de formação realizados na universidade como na escola. A participação colaborativa em todos os momentos docentes na escola possibilita que os residentes compreendam os diferentes âmbitos apresentados por Imbernón (2011).

O desenvolvimento profissional de professores, ainda em processo de formação inicial, tem sido o foco do planejamento das ações do nosso núcleo no programa RP. Para tanto, temos estão sendo realizadas atividades que proporcionem aos residentes desenvolver uma perspectiva crítica acerca da docência. Para Nóvoa (1995, p. 25), "[...] a formação deve estimular uma perspectiva crítico-reflexiva, que forneça aos professores os meios de um pensamento autônomo e que facilite as dinâmicas de auto-formação participada [...]" e que, de alguma forma, contribuem para as necessárias tomadas de decisão inerentes à prática de sala de aula.

As situações inesperadas que ocorrem na vivência do dia a dia da escola foi uma marca constitutiva da docência. Os residentes relataram com detalhes situações que surgiram e que desencadearam uma mudança no planejamento:

Iniciei meu estágio, estava nervosa, ansiosa, me preparei por várias semanas, escrevi tudo o que eu ia dizer em sala de aula, durante a aula ia passar um vídeo aos alunos, porém, ao chegar na escola, a professora me avisou que o aparelho da sala estava com problema e, para passar teria que ter reservado outra sala. Fiquei frustrada com a situação, logo no primeiro dia, foi uma decepção tão grande que decidi pular o vídeo e ir adiante no planejamento. 
O desabafo da residente faz emergir uma situação preocupante nas escolas, a falta de planejamento coletivo, de modo especial, nesse caso, temos a inserção de um residente que não tem todo o conhecimento do contexto escolar, da infraestrutura, então, mais uma vez a necessidade de um diálogo. As situações inesperadas que ocorrem no dia a dia das escolas de educação básica, assim como essa que foi relatada, refletem dificuldades no processo de gestão do trabalho docente, em especial, pela falta de comunicação. Conforme apresentado pela residente, a situação que ela passou poderia ter sido resolvida se a informação tivesse chegado a tempo. Compreendemos que a escola precisa se reconhecer como uma comunidade de aprendizagem, em que professores, funcionários e alunos se identifiquem no coletivo e trabalhem pelo bem comum, porém isso ainda está andando a passos lentos, apesar de, na atualidade, termos meios de comunicação mais eficazes.

Nesse sentido, Alarcão (2011, p. 38) contribui com o que foi apresentado ao afirmar que

[...] as escolas ainda não compreenderam que, também, elas, têm de se repensar. Permanecem na atitude negativa de se sentirem defasadas, mal compreendidas e mal-amadas, ultrapassadas, talvez inúteis. Quedam-se à espera que alguém as venha transformar. E não perceberam ainda que só elas se podem transformar a si próprias. Por dentro.

Em nossas vivências como formadoras e há algum tempo envolvidas com programas de iniciação à docência na universidade, temos identificado que a inserção de tais práticas, como o RP, pode contribuir para movimentar as escolas no sentido de construir/reconstruir ideias e gerar compreensões acerca do trabalho docente. E é nessa perspectiva que temos apostado como coordenadoras, a de promover na escola espaços para diálogos, não apenas entre os professores da área de Ciências da Natureza, mas para além, envolvendo 
todos os professores. Ainda, o acompanhamento dos residentes nas escolas, por meio de visitas regulares, tem contribuído para aproximar o nosso trabalho de formadoras e compartilhar as perspectivas que temos assumido na formação de professores.

Nas leituras dos DBs, identificamos a falta de diálogo nas escolas como principal problema, sendo esse um aspecto recorrente relatado pelos residentes, conforme destacado, também, por outro residente:

Confesso que foi muito difícil entrar em sala de aula como professor e não mais como aluno, ainda mais com o planejamento todo organizado para trabalhar duas horas aula e, ao chegar na escola, uma hora foi utilizada para momento de leitura, sendo que ninguém tinha me avisado disso. Fiquei um pouco decepcionado, mas já tinham me falado dessas situações inesperadas que vão ocorrendo na escola.

Nesse sentido, compreendemos, como Alarcão (2011, p. 47), que " $[. .$.$] o professor não pode agir isoladamente na sua escola.$ É nesse local, o seu local de trabalho, que ele, com os outros, seus colegas, constrói a profissionalidade docente". Assim, as vivências dos residentes e dos preceptores nas escolas, no período de imersão em sala de aula, tiveram como objetivo desenvolver a coletividade. Para tanto, os planejamentos de ensino e toda a organização para o trabalho em sala de aula foram acompanhados por nós, coordenadoras, e pelos preceptores. Porém, identificamos que os preceptores, como professores efetivos da escola, também não tinham o costume de dialogar acerca das situações inesperadas no sentido de buscar resolvê-las. Acreditamos que uma organização coletiva mais efetiva das ações que são desenvolvidas na escola possa, de alguma forma, minimizar algumas das contradições vivenciadas entre o planejamento e a ação. Claro que o fazer docente implica outras peculiaridades que 
vão além dessas questões, mas, para professores iniciantes, tais divergências já constituem dificuldades e/ou decepções frente à profissão.

\section{b) Coletivo e Desenvolvimento Profissional}

[...] Precisamos compartilhar conhecimentos pedagógicos com os colegas, é um desafio, mas precisamos tentar [...]

[...] Escrever um relato é um desafio, pois não estou habituada com o processo de escrita e não me sinto preparada [...]

Essa categoria emergente retrata de modo especial o desenvolvimento profissional dos preceptores e indicia marcas do desenvolvimento profissional docente. Ressaltamos que o objeto analisado, o $\mathrm{DB}$, não era um instrumento da rotina dos professores participantes do programa. Assim, foram realizados momentos de formação acerca da importância do diário, por meio da leitura e da socialização do livro El diario del Profesor: un recurso para la investigación en el aula, de Porlán e Martín (2000).

Destacamos que as leituras e as escritas realizadas pelos preceptores foram menos intensas do que as escritas dos residentes nos DB, compreendemos que a escrita, em especial, a escrita reflexiva, não é uma prática realizada pelos professores que estão em atividade na educação básica, como bem retrata a percepção de uma preceptora "[...] não estou habituada com o processo da escrita". Ou seja, toda a caminhada está sendo um aprendizado, um desafio de trazer para o contexto de formação, com uso da escrita reflexiva, o professor da educação básica, que, em sua maioria, tem um distanciamento de tal prática, e isso mostra a importância do programa e das ações que estão sendo desenvolvidas e que vão fortalecendo o desenvolvimento profissional.

Ainda, entre outros escritos, destacamos "[...] Precisamos compartilhar conhecimentos pedagógicos com os colegas, é um desafio", tal 
posicionamento retrata a barreira que precisa ser rompida de o professor se sentir pertencente a um coletivo e de socializar as suas práticas, pois, historicamente, há um isolamento do seu fazer pedagógico.

Corroboramos com as ideias de Imbernón (2016), ao afirmar que a atividade docente

[...] caracterizou-se historicamente pelo isolamento em salas de aula fechadas, pela individualização do ensino, pela falta de projetos compartilhados e pela fragmentação do conhecimento em matérias e especialidades estanques. (IMBERNÓN, 2016, p. 54)

Nesse sentido, destacamos que as vivências nas escolas, por meio das visitas que realizamos e a escrita da professora, dão indícios do processo de isolamento relatado por Imbernón (2016). Quanto a isso, reforçamos as ideias de Bolzan (2002, p. 15), segundo o autor, "[...] a escola é um dos lugares onde os conhecimentos podem ser compartilhados". Dessa forma, temos potencializado e instigado os discursos dos preceptores, professores de escola, para que possam compartilhar mais, dialogar mais e, assim, sair do processo de individualização do ensino.

Quanto a isso, acreditamos que, pelo processo formativo vivenciado, temos conseguido avançar, conforme apresentado por um preceptor:

No início, estava apreensiva com a situação de vir para a universidade participar do programa. Mas, hoje, me sinto realizada de poder compartilhar meus conhecimentos da prática com todos. Percebi o quanto é importante o que eu faço em sala de aula, falta a gente ter mais espaços como esse para falar sobre nosso dia a dia na escola.

Nessa direção, temos percebido o quanto a aproximação da escola com a universidade, por meio da participação dos preceptores 
no programa RP, tem contribuído para movimentar a escola, levar os professores a pararem para refletir acerca de suas práticas, refletir sobre o trabalho docente. Bolzan (2002, p. 17) contribui quanto a isso ao afirmar que

[...] esse processo de reflexão-crítica, feito individualmente ou em grupo, pode tornar conscientes os modelos teóricos e epistemológicos que se evidenciam na sua atuação profissional e, ao mesmo tempo, favorecer a comparação dos resultados de sua proposta pedagógica com as teorias pedagógicas e epistemológicas mais formalizadas.

Ainda, identificamos na escrita de uma das professoras o desenvolvimento do trabalho colaborativo como uma marca da vivência no programa RP:

Precisamos acompanhar, conversar, aconselhar, contribuindo para que a imersão em sala de aula seja positiva. Precisamos contribuir para que o residente/estagiário se abra para a reflexão, a reconstrução de práticas e aprenda no dia a dia da escola. Para isso, precisamos mobilizar os demais professores, todos precisam compartilhar conhecimentos pedagógicos para que todos possam aprender sempre.

A escrita da preceptora revela a preocupação em contribuir com o trabalho do programa ao afirmar a importância do acompanhamento na atuação do residente. Ainda, destaca a necessidade do envolvimento dos demais professores reforçando o trabalho colaborativo. Bolzan (2002, p. 22) afirma que "[...] a construção do papel de ser professor é coletiva, se faz na prática da sala de aula e no exercício da atuação cotidiana na escola. Uma conquista social, compartilhada, pois implica trocas e representações".

Nessa direção, Nóvoa (1995, p. 26) afirma que “[...] o diálogo entre os professores é fundamental para consolidar saberes 
emergentes da prática profissional”. E continua, “[...] a troca de experiências e a partilha de saberes consolidam espaços de formação contínua, nos quais cada professor é chamado a desempenhar, simultaneamente, o papel de formador e de formando" (NÓVOA, 1995, p. 26).

As vivências compartilhadas por meio das ações no programa RP têm evidenciado o quanto os preceptores assumiram o papel de orientadores do processo de formação inicial por meio da partilha de saberes e da troca de experiências, conforme apresentado por Nóvoa (1995). Tal situação tem contribuído muito para o êxito do programa em nosso núcleo. Com isso, reafirmamos que a integração universidade e escola, oportunizado pelo RP, é um caminho promissor para a qualificação da formação de professores fortalecendo tanto a formação inicial como a continuada, pois, ao estabelecer um coletivo com diferentes experiências e olhares para a docência, se oportuniza um movimento de profissionalização e de reflexão na e sobre a prática.

\section{Considerações Finais}

As ações vivenciadas no programa RP têm se tornado experiências relevantes para o processo formativo de licenciandos residentes, professores preceptores e, também, para nós coordenadoras do programa. Como formadoras, temos compartilhado momentos significativos de diálogos, estudos e vivências, que se tornaram marcas constitutivas para nós e para todos os participantes.

$\mathrm{E}$, assim, reafirmamos que ações formativas como essas, que incentivam e qualificam a interação universidade e escola, se tornam políticas educacionais positivas no atual contexto educacional que vivenciamos. De modo especial, destacamos a prática de escrita em DB e os diálogos coletivos como momentos constitutivos da 
docência promovendo a profissionalização do professor. É preciso compreender que os diferentes conhecimentos necessários para a prática do professor precisam ser significados e (re)significados em diferentes contextos, então, é nessa direção que o coletivo estabelecido pelo RP entre residentes, preceptores e professores Formadores se mostra necessário, pois promove planejamentos coletivos, trocas de experiências que se tornam marcas constitutivas em cada um dos participantes e possibilita uma constante (re)significação do ser professor e do processo de ensinar e aprender.

\section{Referências}

ALARCÃO, Isabel. Professores reflexivos em uma escola reflexiva. 8. ed. São Paulo: Cortez, 2011.

ANDRÉ, Marli. Formação de professores: a constituição de um campo de estudos. Educação, [S.l.], v. 33, n. 3, 2010. Disponível em: http://www.redalyc.org/articulo.oa?id=84816931002. Acesso em: 19 maio 2019.

BOLZAN, Dóris Pires Vargas. Formação de professores: compartilhando e reconstruindo conhecimentos. Porto Alegre: Mediação, 2002.

CARR, Wilfred; KEMMIS, S. Teoría crítica de la enseñanza: la investigación-acción en la formación del profesorado. Ediciones Martínez Roca, 1988.

FERREIRA, Aurélio Buarque de Holanda. Novo dicionário Aurélio da língua portuguesa. 8. ed. Curitiba: Positivo, 2010.

GATTI, Bernardete A. Análise das políticas públicas para formação continuada no Brasil, na última década. Revista Brasileira de 
educação, [S.l.], v. 13, n. 37, p. 57-70, 2008. Disponível em: http://2011.redalyc.org/articulo.oa?id=27503706. Acesso em: 19 de maio de 2019.

IMBERNÓN, F. Formação docente e profissional: formar-se para a mudança e a incerteza. 9. ed. São Paulo: Cortez, 2011.

IMBERNÓN, F. Qualidade do ensino e formação do professorado: uma mudança necessária. São Paulo: Cortez, 2016.

LARROSA, Jorge. Tremores: escritos sobre experiência. Belo Horizonte: Autêntica, 2015.

NÓVOA, António. (org.). Os Professores e a sua Formação. 2. ed. Lisboa: Publicações Dom Quixote, 1995.

PORLÁN, Rafael; MARTÍN, Jose. El diario del profesor: un recurso para la investigación en el aula. 8. ed. Sevilla: Diada Editora, 2000.

UFFS - UNIVERSIDADE FEDERAL DA FRONTEIRA SUl. Projeto Institucional Residência Pedagógica: registrado na plataforma Freire em 08/08/2018. 